\title{
Planejamento Estratégico de Tecnologia para PMEs: o Caso de Empresa de Autopeças no Rio Grande do Sul
}

\author{
Paulo Antônio Zawislak \\ Luis Felipe Nascimento \\ Thaise Graziadio
}

\begin{abstract}
RESUMO
O trabalho tem por objetivo testar as características de um instrumento de gestão estratégica aplicado a uma empresa do setor de autopeças, de médio porte, no Estado do Rio Grande do Sul. O planejamento estratégico de tecnologia possibilita o levantamento das características tecnológicas da empresa e a identificação de pontos fracos no seu comportamento. Neste estudo de caso foram investigadas as seguintes etapas do instrumental: definição do problema, mapeamento do ambiente externo, análise da capacidade tecnológica, transformação de informações em soluções, definição da estratégia tecnológica e, finalmente, desenvolvimento e controle de projetos. Verificouse que a empresa realiza praticamente todas as fases do planejamento estratégico, mas de maneira bastante informal; somente a fase de projetos é estruturada. Uma pessoalidade permeia as relações internas, o fluxo de informações subexiste pelo mérito das pessoas e não de um sistema. Este fenômeno só vem a reforçar a informalidade tecnológica, mesmo que relativa, da empresa.
\end{abstract}

Palavras-chaves: planejamento estratégico de tecnologia; indústria de autopeças; pequenas e médias empresas.

\begin{abstract}
This paper proposes to test the characteristics of a framework for strategic management of technology, to be applied in the case of a medium-sized enterprise that produces autoparts in Rio Grande do Sul, Brazil. Through the strategic planning of technology it is possible to map the technological features of a firm and to identify its weak points. The methodology involves the investigation of several stages of the framework: 1) definition of the problem, 2) mapping of the external environment, 3) analyses of the firm's technological capability, 4) ability to transform information into solutions for problems, 5) definition of technological strategy and finally, 6) development and management of the project. The results suggest that most of the stages of the strategic planning framework are followed in this firm. However, except for the project, all the other stages are quite informal (non structured). Internal relations are usually based on people contacts and not formally organized. The information flow is also quite fragile and supported by staff's efforts; there is no systematic communication. This kind of procedure emphasizes the technological informality of the firm.
\end{abstract}

Key words: strategic planning of technology; autoparts industry; small and medium-sized firms. 


\section{INTRODUÇĀO (*)}

A alternativa para a evolução de setores com tecnologias estabilizadas em mercado de competição globalizada passa pela gestão estratégica da tecnologia. Assim como na indústria de autopeças, a gestão estratégica nos demais setores de tecnologia estabilizada está associada à necessidade de reduzir incertezas e resolver problemas que ameaçam a competitividade empresarial ${ }^{(1)}$. De modo simples o planejamento estratégico de tecnologia estabilizada é instrumento de gestão comum à estratégia corporativa, só que tem como objeto a tecnologia e suas fronteiras de evolução.

Este trabalho tem por objetivo testar as características de um instrumento de gestão estratégica em uma empresa de médio porte, fabricante de autopeças no Estado do Rio Grande do Sul. Para a elaboração do instrumento de análise foram estudados os conceitos de tecnologia, capacidade tecnológica, gestão da inovação e planejamento estratégico. A pesquisa procura verificar a funcionalidade do planejamento estratégico aplicado à gestão tecnológica.

Este artigo está dividido em seis seções. A segunda seção apresenta os conceitos de tecnologia, capacidade tecnológica, gestão tecnológica e gestão da inovação. Na seção 3, coloca-se o esquema conceitual de planejamento estratégico de tecnologia estabilizada. Na seção 4, descreve-se o método da pesquisa e a empresa. Na seção 5, são revelados os resultados da análise sobre o instrumento de planejamento estratégico de tecnologia estabilizada de acordo com a realidade da empresa. Na seção 6, são colocadas as considerações finais.

\section{A Tecnologia, sua Evolução e sua Gestão}

Dentro do atual cenário de competição, as vantagens comparativas não se resumem mais na disponibilidade de fatores físicos, como capital, mão-de-obra ou matéria-prima. Mais do que isso, a competição está sendo escrita nos diferentes detalhes que compõem e/ou são acrescidos aos modos de combinar estes fatores, isto é, na própria tecnologia. Mas que é, ao certo, tecnologia?

Diversas são as definições de tecnologia. Elas podem ser estritamente operacionais, como aquelas que dizem respeito ao conteúdo prático das atividades, como podem ser amplas, tratando de relações sociais. Para a abordagem aqui 
proposta, entende-se por tecnologia o como fazer de todo um ciclo produtivo; é a rotina mínima (prescrita em métodos, princípios, máquinas e conhecimentos diversos) necessária para fazer funcionar um processo dentro de padrões de eficiência econômica.

Tendo em vista que tecnologia se associa a conhecimento científico e, mais do que isso, a método científico, surge obviamente a necessidade de constituir uma atividade formalmente organizada para a utilização da tecnologia e, principalmente, para a sua evolução.

\section{Capacidade Tecnológica}

A capacidade tecnológica é o processo de escolha das tecnologias, bem como de escolha dos rumos de modificação assumidos por ela, ou seja, a capacidade de absorção, domínio, adaptação, melhoramento ou inovação de uma tecnologia por parte de uma organização. A capacidade tecnológica visa a resolver problemas não rotineiros, permitindo a sobrevivência da organização em ambiente permanentemente dinâmico. Segundo Lall (1992), a capacidade tecnológica pode ser resumida em três níveis:

. A capacidade tecnológica básica é aquela que toda firma deve possuir para sobreviver em um ambiente dinâmico; trata-se de garantir a continuidade do que já é feito.

. A capacidade tecnológica intermediária é o nível em que a empresa deve conseguir fazer melhor o que ela já faz bem feito. Esta capacidade é representada geralmente pelas atividades de engenharia (de produto e de processo).

. A capacidade tecnológica avançada é o nível superior. Aqui a empresa deverá não somente fazer melhor, mas, principalmente, fazer diferente o que se já se faz. De certa forma, a empresa passa a ser capaz de ditar moda, enquanto nos demais níveis ela é seguidora de moda pré-definida.

Podem-se interligar estes três níveis de capacidade com três estratégias tecnológicas básicas, a saber, da mais avançada para a básica: inovadora (ofensiva ou defensiva), imitadora e seguidora (dependente, tradicional ou oportunista). Estas estratégias estão detalhadas em Freeman (1982).

O estabelecimento de um tipo de capacidade é, na realidade, função do tipo de tecnologia que uma empresa possui. Existem, em linhas gerais, três tipos de tecnologias (Roussel et al., 1992) aos quais se relacionam os três níveis de capacidade:

. A tecnologia nascente é aquela que desponta como solução potencial, é iné- 
dita. Trata-se do momento de nascimento, da inovação propriamente dita.

. A tecnologia paradigmática está em amplo processo de evolução; é o momento em que a inovação passa a ser utilizada por diversos setores mediante processo de difusão: as empresas investem somas importantes na melhoria da tecnologia.

. Finalmente, a tecnologia estabilizada (ou madura) caracteriza-se por ter seus principais problemas já resolvidos. Por ser de domínio público, esta tecnologia tem poucos segredos e trajetórias de evolução. São exemplos de setores, além de autopeças, têxtil, calçados, cimento, alimentação e siderurgia.

É importante ressaltar que não se trata necessariamente de uma análise histórica. Obviamente que toda tecnologia nasce, generaliza-se e estabiliza-se; no entanto as tecnologias dos tipos nascente, em desenvolvimento e estabilizada convivem no mesmo espaço-tempo, seja ele setor, região, país ou mesmo o mundo.

À medida que uma tecnologia é utilizada, surgem problemas relativos ao seu funcionamento. A solução de problemas implica a alteração do funcionamento da tecnologia. Evidencia-se, então, um processo de modificação que, tanto quanto o processo produtivo, pode e deve ser gerenciado. A gestão da modificação da tecnologia é o que se chama gestão da inovação tecnológica.

\section{A Gestão de Diferentes Tecnologias}

Diferente da gestão, por assim dizer clássica, em que basicamente são administrados recursos materiais, a gestão da inovação necessita de um conjunto de técnicas e ferramentas para administrar o conhecimento e a evolução do conhecimento. Em outras palavras, ela está voltada para a administração das informações disponíveis e da criatividade, sendo que a função desta é justamente alterar as informações para uma melhor resolução de problemas, isto é, para a inovação. Gestão da inovação diz respeito aos instrumentos capazes de assegurar a eficiência do processo de modificação de uma tecnologia.

Levando-se em consideração que para cada tipo de tecnologia corresponde uma capacidade tecnológica, uma estratégia, um tipo de informação e uma carga de criatividade, evidenciam-se também diferentes tipos de gestão da modificação dessas tecnologias:

. A gestão de tecnologias nascentes requer grande esforço de inovação, realizado através de $\mathrm{P} \& \mathrm{D}$. A gestão deste tipo de tecnologia deve estar voltada para os meios que garantam seu crescimento. Neste sentido, é necessário levar em conta toda e qualquer fonte de conhecimento e informação. É necessário, para isso, fazer um esforço de prospecção tecnológica. 
. A gestão de tecnologias paradigmáticas, daquelas em pleno processo de difusão e que evoluem em cada nova adaptação feita por um usuário, visa principalmente a competir. Trata-se do esforço de administração do processo de inovação incremental, do conjunto de detalhes técnicos que poderão fazer a diferença no mercado.

- A gestão de tecnologias estabilizadas, aquelas cujo conteúdo é amplamente dominado e na qual a incidência de problemas é muito pequena, deverá estar voltada para tentar descobrir caminhos por onde, aparentemente, não seria possível andar. O perigo, nesta fase de evolução da tecnologia, passa a ser a estagnação. Assim, para evitar ou postergar ao máximo a obsolescência, a gestão deverá administrar os recursos humanos no sentido de imbuir-lhes uma mentalidade de resolução de problemas, isto é, conscientizar as pessoas da necessidade de utilizar muita criatividade para resolver todo e qualquer tipo de problema que impeça a sobrevivência da tecnologia.

Tanto quanto existem diferentes formas de gestão tecnológica, as técnicas e instrumentos empregados na gestão da inovação para tecnologias nascentes, paradigmáticas e estabilizadas também são diferentes.

Assim, diz-se que gestão da inovação é a gestão de todos os conhecimentos, internos ou externos, em estoque ou em criação (criatividade). Qualquer que seja o tipo de tecnologia, sempre haverá um roteiro de gestão para ser seguido. Com isso é possível organizar-se a atividade de resolução de problemas e garantir a eficiência do esforço de inovação. Quatro são os passos fundamentais de todo e qualquer processo de gestão:

1. Formação de times de solução de problemas: o uso de times para integrar pessoas de diferentes áreas é boa alternativa para um processo sinérgico de criação de novos conhecimentos, isto é, de inovação.

2. Mapeamento do ambiente externo: toda atividade de resolução de problemas, para ser efetiva (levar à inovação) deverá ter como espelho o que já existe e, quando possível, aquilo que está por surgir. É fundamental conhecerem-se as oportunidades e ameaças tecnológicas, porém mais do que simplesmente realizar benchmarking, a empresa deve constituir verdadeiros canais de informação com o mundo externo.

3. Mapeamento da atividade de resolução de problemas: antes de poder administrar o processo de modificação da tecnologia, é preciso conhecê-lo em seus detalhes. Para isso, observam-se os processos de solução de problemas, desde a percepção, interpretação, busca e aplicação da solução, não importando se o processo é formal ou informal. 
4. Projeto: a partir das informações, conhecimentos, criatividade e planejamento, programa-se a execução do projeto (solução). Isto envolve a determinação de objetivos, metas, papéis dos participantes, cronograma, orçamento, necessários para a otimização da atividade de inovação.

O Quadro 1 resume as principais características das tecnologias e dos tipos de gestão.

\section{Quadro 1: Tecnologias, Capacidade Tecnológica e Gestão da Inovação}

\begin{tabular}{l|l|l|l|l|l}
\hline $\begin{array}{l}\text { Tipo de } \\
\text { Tecnologia }\end{array}$ & $\begin{array}{l}\text { Quantidade } \\
\text { Problemas }\end{array}$ & $\begin{array}{l}\text { Trajetória } \\
\text { Tecnológica }\end{array}$ & $\begin{array}{l}\text { Suporte } \\
\text { para } \\
\text { Inovação }\end{array}$ & $\begin{array}{l}\text { Capacidade } \\
\text { Tecnológica }\end{array}$ & $\begin{array}{l}\text { Gestão da } \\
\text { Inovação }\end{array}$ \\
\hline Nascente & enorme & $\begin{array}{l}\text { baseada na } \\
\text { ciência }\end{array}$ & P\&D & avançada & $\begin{array}{l}\text { gestão de } \\
\text { projetos }\end{array}$ \\
\hline Paradigmática & grande & $\begin{array}{l}\text { intensiva em } \\
\text { processos }\end{array}$ & engenharia & intermediária & $\begin{array}{l}\text { gestão da } \\
\text { tecnologia }\end{array}$ \\
\hline Estabilizada & pequena & $\begin{array}{l}\text { dependente } \\
\text { dos } \\
\text { fornecedores }\end{array}$ & $\begin{array}{l}\text { atividade de } \\
\text { resolução de } \\
\text { problemas }\end{array}$ & básica & $\begin{array}{l}\text { gestão das } \\
\text { pessoas e dos } \\
\text { problemas }\end{array}$ \\
\hline
\end{tabular}

Enfim, times, redes de informação e conhecimento da estrutura interna de resolução de problemas constituem condição sine qua non para a gestão da inovação. Mas o que garante a eficiência do projeto é mesmo o planejamento estratégico de tecnologia - PET.

Buscando respaldo nesta consagrada ferramenta de estratégia e marketing, o importante é utilizar as informações externas e internas para garantir aquele que deverá ser o caminho mais adequado entre a tecnologia utilizada pela empresa e a solução almejada (nova tecnologia). Este caminho é o projeto. Através do PET torna-se mais fácil transformar necessidades de solução em soluções de fato, conduzir a estratégia tecnológica da empresa (inovadora, imitadora ou seguidora), realizar verdadeiro projeto de busca e aplicação de soluções (pesquisa e desenvolvimento). 


\section{Planejamento Estratégico de Tecnologias Estabilizadas}

Segundo Kotler (1991), o planejamento estratégico é processo gerencial que permite desenvolver e manter adequação razoável entre os objetivos e recursos da empresa e as mudanças de mercado. O objetivo do planejamento estratégico é orientar e reorientar os negócios e produtos, de modo que gerem lucros e crescimento satisfatórios. Kotler (1991) define oito etapas de um planejamento estratégico: missão do negócio, oportunidades e ameaças, pontos fortes e fracos, objetivos e metas do negócio, estratégias do negócio, planos de ação, implementação, feedback e controle.

Enquanto o planejamento estratégico corporativo tem por objetivo orientar e reorientar os negócios e produtos da empresa, o planejamento estratégico de tecnologia visa a orientar e reorientar uma tecnologia, de modo que esta solucione problemas. Seguindo a analogia com o planejamento estratégico corporativo, podese subdividir o planejamento estratégico de tecnologia em oito fases.

A primeira fase é a definição do problema por resolver/prever, em que se requer amplo conhecimento da tecnologia em uso, envolvimento dos funcionários, etc. Nesta fase é fundamental identificar o que a empresa considera como problema, os tipos de problemas (rotineiros e não-rotineiros), as pessoas que detectam os problemas, e as medidas tomadas para resolvê-los. Também se observam as causas e conseqüências dos problemas, bem como a freqüência com que eles ocorrem. De posse dessas informações, analisam-se os procedimentos adotados para a busca de soluções.

A segunda fase é o mapeamento do ambiente externo, uma tentativa de posicionar a tecnologia da empresa no mercado concorrencial (benchmarking). Isto implica analisar o comportamento tecnológico adotado pela empresa com relação a seu próprio setor, tanto no contexto nacional como internacional.

O mapeamento da capacidade tecnológica da empresa é a capacidade de resolver ou prever problemas. Nesta terceira fase do planejamento estratégico de tecnologia, são identificados os tipos de problemas que a empresa consegue resolver por conta própria e quais são aqueles para os quais ela precisa de auxílio externo.

A quarta fase caracteriza-se pela transformação das informações externas e internas para a solução ou previsão do problema. Investiga-se o processamento de informações, tipos de atividades realizadas, freqüência, resultados, divulgação, e as formas de registro da gestão das informações. 
Na quinta fase, a empresa deve definir os contornos da ação de resolução de problemas, ou seja, a estratégia tecnológica. A partir da relação entre negócios e tecnologia disponível, a empresa estabelece aonde pretende chegar. A meta desta estratégia tecnológica pode ser de três tipos: inovadora, imitadora ou seguidora. Cada uma delas reflete a combinação mais adequada entre necessidades e potencialidades. Por exemplo, uma empresa com elevados custos de P\&D não pode basear sua estratégia tecnológica no simples cumprimento de uma tendência. É, pois, necessário compatibilizar um mecanismo de funcionamento (um caminho) para a relação entre o que está disponível e o que se quer.

A fase de elaboração de projeto pressupõe o emprego de métodos específicos, cronograma e orçamento. Abrange o momento do surgimento da idéia, definição do papel do líder de projeto, determinação do hiato existente entre o projetado e o implantado, até os desvios identificados no projeto e as medidas de eficiência dos projetos.

\section{Quadro 2: Etapas do Planejamento Estratégico de Tecnologias Estabilizadas}

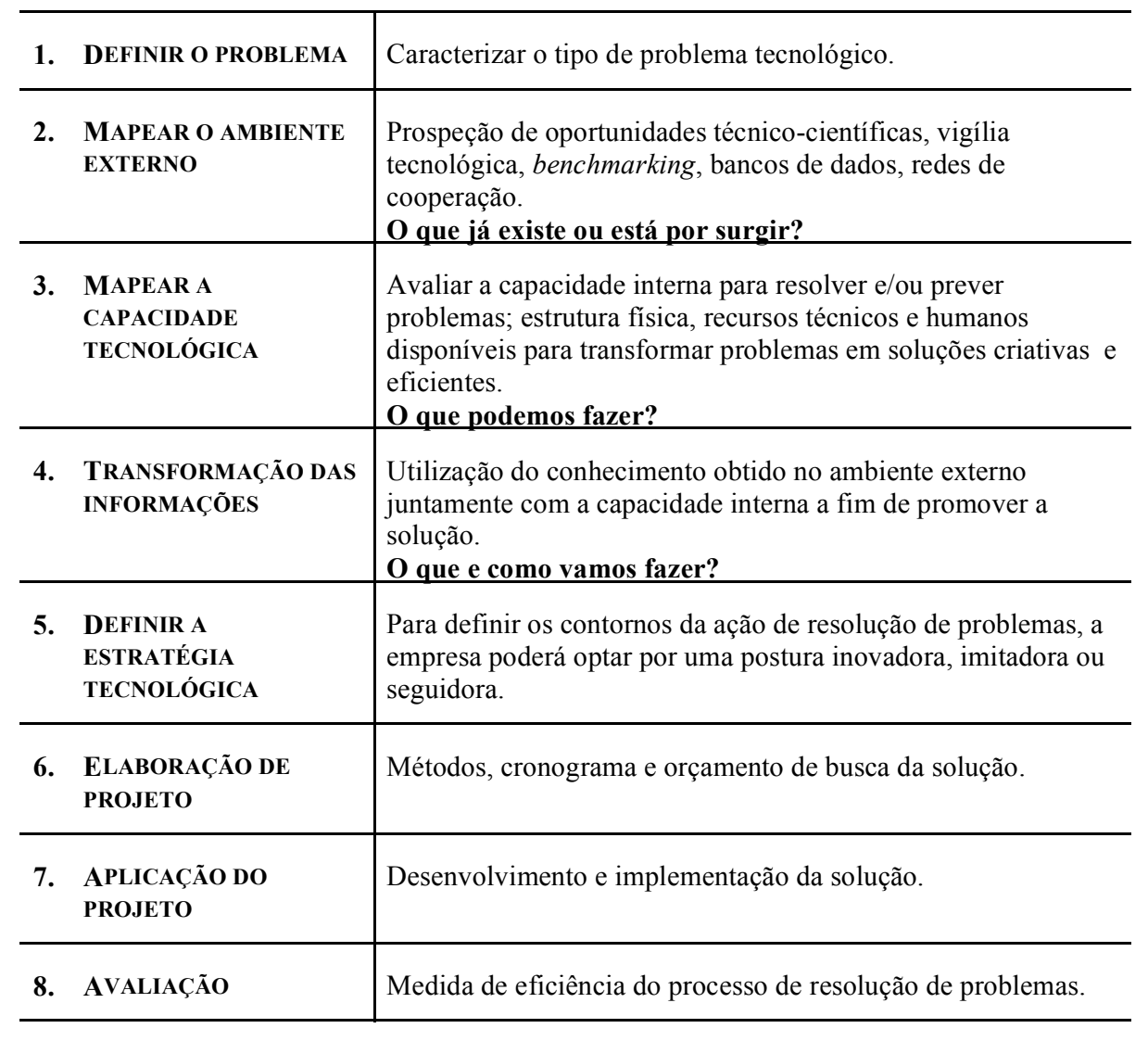


Nas demais fases, sétima e oitava, acontece a aplicação do projeto e a avaliação da eficiência do processo de resolução de problemas. A avaliação visa a controlar e ajustar o processo para minimizar a ocorrência de problemas.

No Quadro 2 estão descritas as etapas do planejamento estratégico de tecnologia estabilizada, bem como algumas das questões-chaves utilizadas na pesquisa.

\section{Método de Pesquisa}

Foi empregado o método de estudo de caso por permitir análise ampla da situação e a comprensão de diversos aspectos relacionados entre si. Os dados foram coletados por entrevista de profundidade, elaborada a partir do esquema conceitual do planejamento estratégico de tecnologia estabilizada, com posterior análise qualitativa. Foram realizadas entrevistas individuais com cinco membros da empresa (diretor, dois gerentes e dois líderes de projeto), além de diversas visitas à fábrica.

A empresa, de médio porte, fornece peças e sistemas para montadoras de automóveis. As atividades iniciaram na década de 70, sempre caracterizadas pelo desenvolvimento de produtos adequados ao mercado. Detentora de conhecimentos e métodos (tecnologia) eficientes, a empresa teve de enfrentar uma fase de estagnação no início da década de 80 . Para recuperar-se, buscou, através do estabelecimento de uma joint-venture com grande empresa americana, um novo padrão tecnológico.

Na ocasião do estabelecimento da joint-venture, a empresa brasileira já tinha tradição no desenvolvimento de produtos e processos e passou a diferenciar seus produtos. Mas a transferência de tecnologia não foi absoluta; a diferença na escala de produção entre a parceira (20.000 unidades/dia) e a empresa brasileira (800 unidades/dia) exigiu adaptações.

Inicialmente a joint-venture visava ao acesso de novos mercados no Brasil, mas a relação entre as empresas evoluiu para uma relação simbiótica. A empresa brasileira passou a receber quase toda a tecnologia de produtos da parceira americana (benchmark internacional), o que garantiu o acesso às tecnologias mais modernas. Isso propiciou à empresa brasileira o aprimoramento de sua capacidade de adaptação, ela ganhou agilidade no desenvolvimento de processos e tornouse um exemplo para a gigante americana, que até então tinha uma estrutura pouco flexível. A empresa brasileira também influenciou a parceira no que se refere à flexibilidade para atender clientes variados (GM, FIAT, FORD, VW); a parceira que atendia apenas a GM passou a diversificar suas atividades. 
No início da década de 90, com o processo de globalização da economia brasileira, a empresa foi forçada a reestruturar-se internamente. A preocupação com a qualidade resultou na certificação ISO 9001 e na recuperação da posição de destaque no cenário nacional.

\section{Aplicação do Planejamento Estratégico de Tecnologia}

\section{Definição do Problema}

Para analisar o processo de definição de problemas, foram observadas as experiências de uma das minifábricas da empresa. Há problemas na linha de produção, no fornecimento de matéria-prima, na mão-de-obra e na manutenção.

Para resolver parte dos problemas com materiais (peças e componentes comprados), a empresa adotou há dois anos a ferramenta MRP II - manufacturing resource planning, mas nem tudo foi solucionado. Conforme explicou o gerente da minifábrica, o tempo de estoque ainda é grande, 90 dias e mais 30 dias, sendo a meta reduzir para 30. Também o fornecimento de matéria-prima (alumínio) é um potencial problema, pois há apenas um fornecedor e o desenvolvimento de novos fornecedores exige trabalho longo de preparação.

As novas linhas de produção são as mais problemáticas, pois é exatamente na fase de implantação e adaptação da tecnologia que surgem obstáculos não previstos. Um exemplo disto são as compras de equipamentos; já houve casos de compras de equipamentos sub-dimensionados ou que não se adequavam às necessidades. As falhas foram analisadas e serviram como lição. Atualmente, a análise de situações que envolvam decisões como esta é bem mais ampla.

Também foram mencionados problemas com relação à qualidade de produtos. Em geral, os defeitos são detectados pelos próprios operadores durante a produção, mas também podem ser detectados somente no final, quando o produto já está acabado. Neste caso quem percebe as falhas são inspetores da qualidade ou a auditoria interna. De acordo com o gerente de manufatura, para cada tipo de situação, há procedimentos específicos. Alguns exemplos estão detalhados na seção que trata da capacidade tecnológica da empresa.

\section{Mapeamento do Ambiente Externo}

A empresa mantém com seus clientes uma relação estreita; segue especificações determinadas por eles quanto à qualidade e tecnologia, e organiza seu ritmo de 
produção de acordo com o ritmo dos clientes. Em compensação, eles são importantes fontes de informação.

Há preocupação de conhecer o que existe no mercado sobre as tecnologias de produto e processo, mas é da parceira americana que vem a maior parte das informações sob a forma de desenhos, especificações de produtos e peças, programas de intercâmbio de técnicos e gerentes, treinamento de pessoal na sede da empresa parceira. São mantidos contatos por meio de teleconferência, fax, telefone, além de contatos pessoais. A parceira também envia constantemente material (por exemplo jornais) sobre as tendências de mercado. De certa forma, estas iniciativas revelam o primeiro passo para a prospecção e vigília tecnológica.

Muitas vezes as informações partem dos fornecedores de insumos, que sugerem soluções alternativas em função da sua própria experiência no mercado. Outra fonte de informação é a engenharia reversa em produtos de concorrentes; o departamento de marketing coleta e analisa os produtos do mercado, e transmite informações para o departamento de produção. Para conhecer os processos utilizados pelos concorrentes, a empresa costuma recrutar pessoal. Eventualmente a empresa faz uso de serviços de universidades e centros de pesquisa para assuntos de engenharia e estatística.

O problema está no uso dessas informações. Salvo os casos em que as informações são repassadas pela parceira em forma de pacote, as informações e os conhecimentos existentes na empresa são subaproveitados. Não há fluxo organizado de dados; prevalece o pessoalismo e a informalidade. Isto acaba atrapalhando a difusão de conhecimento.

\section{Mapeamento da Capacidade Tecnológica da Empresa}

A capacidade tecnológica da empresa é medida pela sua capacidade de resolver problemas. Neste caso, percebeu-se que um dos maiores problemas da empresa é a assimilação de tecnologia (projetos da parceira) e sua adaptação ao contexto brasileiro (menor escala de produção, equipamentos diferentes, materiais com outras especificações, etc). A adaptação implica a solução de variados problemas. Para isso a empresa mantém a função de engenharia de projetos, produtos e processos totalmente estruturada. Pode-se dizer que a maior parte dos problemas que ocorrem em projetos e produção são resolvidos internamente. Os projetos de novos produtos e processos são gerenciados segundo os princípios da engenharia simultânea, em que estão envolvidos também os fornecedores e clientes.

Quanto à solução de problemas relativos à qualidade dos produtos, são empregadas várias formas de inspeção: pelos próprios operadores, por inspetores da qualidade, pela auditoria interna; esta última com periodicidade semanal, quinze- 
nal e mensal. As peças com defeitos são retiradas da linha de produção e depositadas em locais determinados (mesas amarelas e vermelhas) e todas as manhãs, os inspetores e os funcionários do setor analisam as peças, verificando as causas dos defeitos. A solução dos problemas pode vir de uma das áreas de suporte, isto é, manutenção, controle de qualidade ou engenharia de manufatura.

Para a análise de causas e para a resolução de problemas, são utilizadas ferramentas da qualidade como o diagrama de Pareto, CEP, MASP, PDCA, times de solução de problemas, etc. $\mathrm{O}$ uso destas ferramentas costuma ser fortemente recomendado pelos clientes. Outra medida trata da criação de um plano de sugestões para premiar idéias e soluções de funcionários; as sugestões implantadas são remuneradas conforme o retorno que proporcionaram à empresa. Na opinião de um dos engenheiros encarregado da manufatura, o plano é importante ferramenta de correções de problemas, mas ainda precisa ser incrementado e emendado em alguns pontos.

Há controle estatístico de dados sobre as peças defeituosas no final do processo, mas não há registro de dados sobre o índice de retrabalho na produção. Em alguns equipamentos estão instalados dispositivos error profing. Contudo há preocupação de melhorar o controle e, para isso, vão surgindo várias iniciativas. Atualmente está sendo implantado o programa first time quality em operações críticas; em breve todas as células terão dispositivos à prova de erros. Visando à melhoria contínua, são feitas reuniões periódicas para discutir problemas, além do uso de técnicas como time de satisfação do cliente e outras ferramentas de controle de qualidade. A médio prazo será aumentado o número de máquinas automatizadas, a fim de reduzir erros humanos, otimizar a produção e até mesmo agilizar o preenchimento dos relatórios. A idéia é também interligar as máquinas de controle numérico em rede, de modo que o gerente tenha todas as informações sobre a produção do monitor da sua sala. Em suma, a empresa investe em técnicas que indicam a ocorrência de problemas e ajudam a reduzi-los, mas não existe agilidade similar quanto ao foco ou causa dos problemas.

A empresa possui capacidade para validar um de seus produtos, isto é, testar e garantir a eficiência do novo produto conforme normas técnicas de segurança e especificações do projeto. Mas os demais produtos precisam ser validados nos centros técnicos da parceira americana. Isto demonstra que, mesmo tendo determinado nível de capacidade tecnológica, ainda persistem traços de dependência para com o parceiro externo, o que impede maior autonomia em projetos.

Enfim, considera-se que a empresa possui capacidade tecnológica no sentido de desenvolver novos projetos e adaptar tecnologias transferidas da parceira (alterações em equipamentos, processos, material, técnicas, etc). Nestes termos, fica caracterizada a existência de uma capacidade tecnológica intermediária. 


\section{Transformação das Informações em Resoluçōes de Problemas}

As informações internas residem essencialmente em pessoas-chaves que dominam o processo; o veículo de informação está baseado em pessoas e não em sistemas formais. Atualmente esta situação parece estar mudando. Há preocupação de ampliar a participação dos funcionários na divulgação das informações e em processos decisórios. Se, por um lado, o fluxo de informação é informal e tem nas pessoas sua rede de informação, por outro lado o processo de decisão de um projeto ainda é rígido e esbarra na hierarquia financeira. Enquanto o projeto não estiver balizado, o seu início não é autorizado.

A gestão de informações externas dá-se basicamente por meio de contatos de técnicos que participam dos estágios na parceira americana. Quando alguma informação é coletada durante visitas a feiras e empresas no exterior, elas são catalogadas, circulam pelos interessados e posteriormente são arquivadas.

\section{Estratégia Tecnológica}

Tendo como principais clientes as montadoras, a empresa está consciente da necessidade de competir em preço, flexibilidade (de entrega, de produto e de processo) e rapidez na entrega de produtos. Estas são medidas de qualidade e condição sine qua non para participar do mercado automobilístico. Outra preocupação da empresa é tornar-se fornecedora sistemista, ou seja, produzir sistemas completos (módulos do automóvel), a fim de enquadrar-se nas tendências atuais do mercado.

Para tanto foram concluídas recentemente duas novas fábricas, que produzirão peças que complementam a linha de produtos da empresa. Também está sendo montado um centro técnico com a finalidade de validar todos os produtos internamente e, assim, dispensar a estrutura da parceira americana. Esta parece ser outra tendência atual; segundo a base de dados ANPEI (1996), as empresas do setor priorizam gastos com estrutura para a realização de ensaios, testes e análises técnicas.

No que se refere à tecnologia utilizada pela indústria de autopeças no Brasil, o diretor considera que a empresa faz parte do primeiro time, mas não é a melhor. Embora seja reconhecida, ela ainda não é considerada benchmark pelos concorrentes.

Em suma, a estratégia tecnológica desta empresa é um mix de seguidora e adaptadora. Seguidora no que diz respeito à tecnologia implícita no produto, que é repassada pela parceira; as adaptações de produto existem, mas são em menor número. Já com relação à tecnologia de processo, a empresa pode ser considerada 
adaptadora e eventualmente inovadora, pois há grande esforço de modificação da tecnologia.

Esta dualidade pode ser notada pelo número de novos projetos desenvolvidos. De 1985 a 1990 a empresa introduziu apenas dois novos produtos, ou seja, dois projetos em cinco anos. Mas atualmente estão sendo desenvolvidos oito projetos simultaneamente.

\section{Elaboração de Projetos}

Praticamente todos os projetos de produto são provenientes da parceira, mas há casos de desenvolvimento totalmente interno (por exemplo, um produto para a FORD). Os projetos têm origem de duas formas: para atender à demanda (pull) ou como investimento estratégico, a fim de dominar determinada tecnologia (push).

O Departamento de Marketing responde pela análise de viabilidade econômica do projeto e pela pesquisa sobre a disponibilidade tecnológica interna para desenvolver o projeto. Também são feitas pesquisas de mercado para conhecer o interesse de clientes, sua opinião e possíveis aplicações. Após terem sido afinados alguns pontos, os custos são avaliados, e uma proposta é entregue ao cliente.

Formalmente, um projeto inicia-se com a aprovação da Diretoria ou com a formalização do cliente. A rotina de elaboração de um projeto segue um manual interno, onde estão colocadas todas as normas. Por exemplo, definição do nome do projeto (pois toda a empresa tem de conhecer o projeto por um único nome); de um líder para o projeto (não necessariamente o autor da idéia); definição de um time multifuncional, definição de tarefas e responsabilidades. Dependendo do tipo de projeto, o líder pode ser alguém do setor de vendas, da produção, etc, mas é importante que o líder conheça muito bem a empresa e consiga formar um time, negociando com os demais setores da empresa (produto, manufatura, qualidade, compras, logística, custos, pós-vendas, etc). Precisa também ser capaz de estimar custos e definir um perfil do processo em curto prazo.

A empresa utiliza também ferramentas próprias para analisar todos os pontos do projeto. Tendo os dados iniciais do projeto, é montada a estrutura do produto; o Setor de Custos participa da análise de valor na fase inicial do projeto e, posteriormente, o marketing avalia as mudanças sugeridas pela análise de valor. A próxima etapa é a pré-definição de manufatura: alocação de mão-de-obra, adequação de equipamentos às necessidades, espaço físico para desenvolver o projeto, capacidade ociosa da fábrica, e a situação do concorrente. A seguir são definidos o layout e o cronograma.

Em seguida, o líder do projeto reúne-se com a Diretoria para vender a idéia, ou 
seja, apresentar a proposta e negociar a implantação do projeto. Junto com a aprovação do projeto é definido um orçamento e um prazo de implantação. A negociação de projetos com clientes é processo lento, estendendo-se até dois anos, devido a muitas variáveis envolvidas na viabilidade econômica dos projetos. Para decidir sobre desenvolver internamente ou comprar tecnologias, a empresa utiliza a técnica de elaborar cenários.

Antes da fase de produção propriamente dita, são feitos protótipos para testes e validação; revisam-se as especificações, realiza-se o treinamento dos operadores. Ainda nesta fase o cliente visita a fábrica para assistir à produção de um lote piloto. O time que trabalhou na elaboração do projeto desfaz-se quando se inicia realmente a produção. O cumprimento da tarefa desta equipe não implica apenas resolver os problemas da implantação de um novo projeto, mas também fazer com que uma idéia se transforme em produto e garantir que ela chegue até o cliente.

\section{Aplicação do Projeto e Avaliação da Eficiência do Processo}

Como já foi exposto acima, a estrutura para proceder ao desenvolvimento de projetos é formal e organizada. Os procedimentos são totalmente documentados, desde o planejamento até o início da produção.

De modo resumido, são estabelecidas as seguintes etapas: aprovação do desenvolvimento da idéia, escolha do líder do projeto e definição do time, estudo de viabilidade econômica, mercadológica e técnica, elaboração de cronograma preliminar, pré-definição do produto e do processo (mão-de-obra e equipamentos), análise da concorrência, planejamento do desenvolvimento (cronograma e orçamento), aprovação do planejamento, aquisição de recursos (técnicos e humanos) necessários, qualificação do fornecedor, análise de possíveis falhas, construção do protótipo, validação, revisão do projeto, elaboração de desenhos para a fase de produção, liberação do produto, planejamento da produção, aprovação de equipamentos adquiridos, elaboração de manual e kit de serviços, teste dos equipamentos, validação do processo, revisão do processo, liberação para lote piloto, lote piloto, certificação pelo cliente, liberação para a produção.

Existem alguns mecanismos para detectar pontos críticos de falhas que interrompem o processo, reduzindo possíveis perdas de tempo e dinheiro. Todas as fases são acompanhadas em reuniões periódicas do time. Neste contexto, a eficiência do processo é medida basicamente pelo cumprimento do cronograma e do orçamento previsto. 


\section{Consideraçóes Finals}

O planejamento estratégico de tecnologia permite um levantamento global das características tecnológicas de uma empresa, identificar possíveis pontos fracos no comportamento tecnológico, bem como capturar o melhor cenário de desenvolvimento de sua tecnologia com relação à sua própria estratégia de negócios. Este instrumental permite, então, identificarem-se as necessidades de gestão tecnológica de uma empresa.

Mais do que isso, sua aplicação visa a reduzir os custos de transação na realização de projetos, ou seja, os custos que todo o processo (no caso o de projeto) incorre devido ao hiato existente entre o que seria uma gestão ótima e o que é a gestão praticada (quando o é!). No que diz respeito à evolução de tecnologias, a aplicação do planejamento estratégico, em linhas gerais, visa a reduzir os seguintes custos de transação:

. erro no foco do problema a ser solucionado;

. erro na definição do problema;

. erro no uso de informações externas;

. erro na adequação de uma estrutura tecnológica à tecnologia em uso;

. erro na transformação de informações externas e internas em soluções de problemas;

. erro na concordância entre estratégia tecnológica e estratégia de negócios;

. erro na elaboração, desenvolvimento e controle de projetos.

Vale salientar que nesta pesquisa não foi feita a aplicação do instrumento de planejamento estratégico de tecnologia. Para este caso, utilizavam-se apenas as fases do planejamento estratégico tecnológico para caracterizar a sua validade enquanto instrumento de gestão e como ferramenta de identificação das características tecnológicas da empresa.

Assim, notou-se que duas características tecnológicas persistem na empresa. A primeira trata da existência de uma colcha-de-retalhos estratégica para a tecnologia. Praticamente todas as fases do planejamento estratégico tecnológico estão identificadas, mas elas são pontuadas por muita informalidade e subaproveitamento formal. A rigor, somente a fase de projetos é formalmente estruturada e respeitada, costurando, por assim dizer, os panos da colcha. 
A segunda diz respeito à pessoalidade que permeia as relações internas. Essencialmente, o fluxo de informações subexiste pelo mérito das pessoas e não em virtude do sistema. Este fenômeno só vem reforçar a informalidade tecnológica, mesmo que relativa, da empresa.

\section{NOTAS}

* Os autores agradecem a inestimável ajuda de Aline Brufato Winckler durante a coleta e análise dos dados.

${ }^{1}$ Este artigo segue a linha de pesquisa do projeto Estratégias e Instrumentos de Gestão para Empresas de Tecnologia Estabilizada no Rio Grande do Sul, realizado pelo NITEC/PPGA/UFRGS. A discussão dos conceitos apresentados na seção 2 está descrita em Zawislak (1996).

\section{ReferênCias BibliográficAs}

ANPEI.

Indicadores empresariais de capacitação tecnológica ano base 1994. São Paulo, 1996.

FREEMAN, C.

The economics of industrial innovation. 2. ed. London : Pinter, 1982.

KOTLER, P.

Administração de marketing : a náli s e, p l a n e j a m e n to, implementação e controle. 2. ed. São Paulo : Atlas, 1991.

LALL, S.

Technological capabilities and industrialization. World Development, v. 20, n. 2, 1992.

ROUSSEL, P. A. et al.

Pesquisa \& desenvolvimento : como integrar P\&D ao plano estratégico e operacional das empresas como fator de produtividade e competitividade. São Paulo : Makron Books, 1992.

ZAWISLAK, P. A.

Gestão tecnológica para empresas de tecnologia estabilizada. In: XIX SIMPOSIO DE GESTÃO DA INOVAÇÃO TECNOLÓGICA (1996 : Brasília). Anais ... São Paulo, 1996. 